\title{
Bridging the Gap: The Value of Science in Coaching
}

\author{
Andrew Langford \\ International Universities Strength and Conditioning Association
}

Science is one of the greatest achievements of mankind. It has saved billions of lives, created astonishing technology, solved global problems, and helped raise the standard of living for all (1). But science is often misinterpreted and misapplied, and sometimes has a negative reputation in the coaching community (2). Part of the problem is that the definition of science varies for different people. We may use the word science to mean the facts that we know about the world - the force of gravity, the mass of an object, the anatomy of the knee etc. These are clear, objective facts, and cannot be disputed. However, we may also use the term science to mean scientific thinking, clear thinking, or critical thinking (3). This is where we might not know the exact facts about something, but we can use the principles of evidence, logic, rationality and reason to make a strong inference about it. We can then test, analyse and evaluate, deciding on what has worked and why. This is evidence-based practice (4). Scientist Carl Sagan put it well when he said, "science is a way of thinking much more than it is a body of knowledge."

We can look at any aspect of S\&C delivery and state that there is no exact scientific study that has been done on it. There are so many variables in terms of the individual or team that you are working with and the environmental influences, that whatever research you read will not match exactly to the situation. But that does not mean that you cannot use an evidence base to inform your decision making and use scientific thinking to rationalise it and determine if it works. For example, if we want to improve the strength of an athlete, we may read the literature and find that there is nothing that matches our athlete's age, training schedule and current abilities. Does that mean that we have no idea what to implement? Of course not. We look at similar scenarios and understand the rationale. We know that higher intensities will have greater effect on maximum strength than lower intensities. We know that at these intensities, athletes will be limited by how many reps they can do. And we know that if we do too many sets, the athlete will be overly fatigued. We can therefore implement what we have determined to be a suitable protocol for that particular scenario. We can then assess and evaluate honestly and adjust as necessary. This is an example of our scientific thinking in action.

But scientific thinking is not just important for planning and basic decision making. The study of psychology shows us that humans are prone to bias and error in many ways. For example, when we coach, we will look for, and cherry-pick, evidence that matches our hopes and beliefs (Confirmation Bias). We will perhaps collect subjective data from some of the athletes who we know are enjoying the training or performing well. When the team wins, we attribute that success to our coaching and programming (Self-serving Bias). When we are designing the next 
phase of training, we will be influenced by the latest posts that we read on social media, or what is currently in vogue (Availability Bias). When looking at injury data or test results we may make false judgements based on sample size and probability (Representativeness Heuristic) (5).

The work of Kahneman and colleagues has highlighted many of these biases and suggests that it is useful to think of our brain as having two operating systems (6). System 1 is fast, instinctive and subject to our emotions, whereas System 2 is slower and more rational. Our evolutionary history has formed System 1 to work well in the context of early human survival on the plains of sub-Saharan Africa. But many of today's decision-making tasks are far different from what the system was originally designed for and is therefore subject to error. Some of these errors can be seen in amazing visual illusions, which you can find if you search for 'cognitive illusions' on the internet. But as explained in the previous paragraph, it is not just our visual processes that are at risk of error. Therefore, if we rely purely on System 1 , and rely purely on our intuitions when coaching, then we may make many errors that go against the evidence and will make us less effective.

The use of scientific thinking (System 2) however, helps immunise us from bias and from potentially deleterious or ineffective practice. It helps us work towards the truth of what works and what does not. It is sometimes said that the best coaches are able to act on 'instinct' and not have to worry about thinking their decisions through (7). Whilst there may be some truth in this, it all depends on what you call 'instinct'. When coaches have worked for decades, with hundreds of athletes, in countless situations, they may have built into their consciousness, through experience, a somewhat 'innate' ability to process relevant information (8). This is the reason why experience is so valuable. It is not something that can be taught in the short-term, and it is why a young, inexperienced coach cannot just rely on their intuition when making coaching decisions. But even experienced coaches should recognise that they are at risk of bias and error. It is important to always enter a situation with an open mind and view the evidence with a sceptical and analytic approach. While individual opinions and feelings are important, they can never overrule empirical evidence.

It is often theorised that there is a conflict between science and coaching, where coaching is postulated as an art (9). While it is true that there is a different skillset involved in coaching, best practice must include an evidence base and the use of scientific thinking. Good, sustainable, S\&C coaching can only exist when the principles of coaching are merged with the principles of science. One of the issues we have continually seen is that the S\&C industry is not viewed as a serious profession (10). This has often led to S\&C coaches being placed lower down the hierarchy of the performance staff, sometimes having to be overseen by the 'more serious' medical department, or forced to be an extension of the coaching staff and used for gruelling discipline of the team (11). By using the principles of science, we can surely offer a more robust and sustainable approach for the S\&C industry. If we have empirical evidence to back up our actions and decisions, then it will be easier for us to be accountable and be taken seriously.

Of course, most of what has been discussed so far has not really touched on coaching ability and coaching skills. Some 
mentors who develop interns and future coaches prefer individuals who have the personality for coaching (12). Qualities such as confidence, rapport building, and work ethic are valued over 'book-smarts'. It is viewed that it is easier to teach a coach the required knowledge of $S \& C$ than it is to teach someone who understands S\&C how to coach. This may be true, or it may be just that we are not very good at teaching people how to coach. Whichever way it is, it is important that we do not forget the values of science. If we are to continue to progress as a profession and have real sustainable impact on our athletes, then we must embrace science and use it as a basis for all that we do.

An interesting discussion point here is that in order to be effective as a coach we have to build relationships and create buy-in. Athletes also suffer from bias, and from an athlete's perspective, they will be more likely to buy-in if they believe in you. For example, the Halo-effect refers to how our first impression can greatly influence our future thoughts and beliefs (13). If, as a coach, we turn up on day one with an athlete and we haven't dressed appropriately, display poor body language, and we speak without clarity, we will no doubt create a lasting impact on that athlete, where anything we do in the future will be less effective. Another factor is the Authority Bias, where someone who sounds like they know what they are talking about is more effective than someone who does not. This is where confidence and knowledge are important as a coach (14). We may also want to get the leaders of a team on board with us first, as their influence on the rest of the team is vital (Bandwagon Effect) (15). It should be made clear here that this is not a moral argument, where we would like to think that people do not judge others based on superficial factors. We would obviously prefer all members of a team to be highly motivated anyway and be willing to work hard and buy in no matter how the coach delivers the information. But anyone who has coached knows that this is not the case. The fact is that athletes do make judgements based on these things and we should therefore do all that we can to work on them and optimise our overall coaching impact. We should also remember that it does not necessarily matter what we intended an outcome to be, what matters in this context is what the actual outcome is. We may have an excellent plan on paper, that should have a large effect on our athletes, but if they do not buy in it may not be as effective as we hoped.

It could be argued that the previous paragraph has nothing to do with science. That it is all about 'soft skills' and working with people. But that is plain wrong. It is science (through psychology) that tells us these factors are important. Science also tells us why they are important from an evolutionary perspective and how we can develop them. We can perhaps say that the 'art' of applying them is not science, but the outcomes and measures of their success certainly are. There may also be an argument that in order to coach effectively, you need to exaggerate the benefits of certain things and pretend to be more knowledgeable and confident than you really are. This can certainly be effective, and the placebo effect can be exploited well on occasion to gain results (16). But I do not think that this has to come at the expense of scientific truth and integrity. Indeed, if we understand the science and rationale behind something, but choose to convey it slightly differently to an athlete in order to gain buy in, and optimise our coaching effectiveness, we 
have then used our rational mind to determine the best plan of action.

Decisions are often not black and white, but instead shades of grey, and in the sporting world with many factors at play, it takes a skilful coach to weigh these up and determine the best plan of action. While I usually aim to be as honest as possible with an athlete, if I decide to exploit the placebo effect or similar, then I will be weighing that up with all of the evidence for how that may impact the athlete, and I will remain accountable for those actions and decisions. It is best in these situations to not just consider the short-term implications, but also how this will affect them in the long-term. On the face of it this may not seem to be a very scientific viewpoint, but on the contrary, I would argue that in order to be effective we must use the evidence available and the principles of science to make these decisions. As any good scientist, we can then test and analyse our data, and then evaluate our findings.

A related problem here is that there is an ethic involved with scientific thinking. That ethic is integrity and being truthful with your actions. Pseudoscience is where a small fraction of scientific knowledge is loosely applied and oversold (17). The S\&C industry is at great risk of this, because in an ever more competitive market, there is a desire to create something new and stand out. We are constantly looking for what is new and what is best. We get swayed by different trends and persuaded by influential personalities. We think that whoever shouts the loudest, must be right. But as the great philosopher Bertrand Russell once said, "the fundamental cause of the trouble is that in the modern world the stupid are cocksure while the intelligent are full of doubt." The coaches who are using principles of science and scepticism will not be $100 \%$ confident in their programming, so they probably will not be shouting the loudest. But they are the ones that I would want to listen to, and it is worth doing the research to determine who they are.

A useful tool to consider here can be referred to as Hume's reasoning (18). Hume's original use for this was in relation to miracles, but the same logic can be applied to any claimed phenomenon. In short, when looking at the evidence for something happening you can either:

1. Accept that it is true

2. Assume that it is a lie

Where the evidence is congruent to the claim, we can cautiously accept option 1 . But where the evidence does not seem to match the claim, we should accept option 2 , unless proved otherwise. The more unlikely, or outrageous, the claim, the more evidence we should require to reject option 2 and accept option 1.

To summarise, science is not merely the facts that we know about the world. It is a process; a way of thinking; a virtue. By infusing science into our coaching, we can ensure our best hope of achieving success. As coaches, we should be enthusiastic to embrace science and have a desire to be part of the scientific community. As educators, perhaps if we focus more on teaching young coaches 'how to think', rather than 'what to think', we may be able to develop a future generation of impactful S\&C coaches who can give our industry a good name. If we can teach our future coaches to be evidence based, sceptical, rational and thoughtful, whilst at the same time helping them develop their coaching skills, perhaps the future S\&C profession will have the great impact that we desire. 


\section{References}

1. Rull V. (2014). The most important application of science: As scientists have to justify research funding with potential social benefits, they may well add education to the list. $E M B O$ reports, 15(9), 919-922. doi:10.15252/embr.201438848

2. https://newsportfuture.com/sportsscience/

3. Holyoak, K., Morrison, R., Dunbar, K., \& Klahr, D. (2012-03-21). Scientific Thinking and Reasoning. In The Oxford Handbook of Thinking and Reasoning. : Oxford University Press. Retrieved 19 Dec. 2019, from

https://www.oxfordhandbooks.com/view /10.1093/oxfordhb/9780199734689.001. 0001/oxfordhb-9780199734689-e-35.

4. Dawes, M., Summerskill, W., Glasziou, P. et al. Sicily statement on evidencebased practice. BMC Med Educ 5, 1 (2005) doi:10.1186/1472-6920-5-1

5. Haselton, M. G., Nettle, D., \& Murray, D. R. (2015). The evolution of cognitive bias. The handbook of evolutionary psychology, 1-20.

6. Kahneman, D. (2011). Thinking, fast and slow. Macmillan.

7. https://www.coachingoutofthebox.com/c oaching-resources/blog/learn-how-tolisten-to-gut-instinct-when-coaching

8. Vergeer, I., \& Lyle, J. (2009). Coaching experience: Examining its role in coaches' decision making. International journal of sport and exercise psychology, 7(4), 431449.

9. https://playerdevelopmentproject.com/c oaching-is-it/

10. https://simplifaster.com/articles/jobsecurity-strength-conditioning/

11. https://www.cbssports.com/collegefootball/news/the-unregulated-world-ofstrength-coaches-and-college-footballskilling-season/

12. https://www.competitivedge.com/special -what-makes-good-coach

13. Nisbett, R. E., \& Wilson, T. D. (1977). The halo effect: evidence for unconscious alteration of judgments. Journal of personality and social psychology, 35(4), 250.

14. Milgram, S., \& Gudehus, C. (1978). Obedience to authority.
15. Nadeau, R., Cloutier, E., \& Guay, J. H. (1993). New evidence about the existence of a bandwagon effect in the opinion formation process. International Political Science Review, 14(2), 203-213.

16. ${ }^{1}$ Beedie, C. J., \& Foad, A. J. (2009). The placebo effect in sports performance. Sports Medicine, 39(4), 313329.

17. Bailey, R. P., Madigan, D. J., Cope, E., \& Nicholls, A. R. (2018). The Prevalence of Pseudoscientific Ideas and Neuromyths Among Sports Coaches. Frontiers in psychology, 9, 641. doi:10.3389/fpsyg.2018.00641

18. Hume, D. (1904). Enquiry concerning human understanding. 